\title{
Comparison of hot spot stress evaluation methods for welded structures
}

\author{
Jung-Kwan Seo ${ }^{1}$, Myung-Hyun Kim², Sang-Beom Shin ${ }^{3}$, Myung-Soo $\mathrm{Han}^{4}$, June-Soo Park ${ }^{5}$, Mahen Mahendran ${ }^{6}$ \\ and Jae-Myung Lee*2 \\ ${ }^{1}$ The Lloyd's Register Educational Trust (LRET) Research Centre of Excellence, Pusan National University, Busan, Korea \\ ${ }^{2}$ Department of Naval Architecture and Ocean Engineering, Pusan National University, Busan, Korea \\ ${ }^{3}$ Hyundai Heavy Industries, Ulsan, Korea \\ ${ }^{4}$ Daewoo Shipbuilding and Marine Engineering, Geoje, Korea \\ ${ }^{5}$ Korea Power Engineering Company, Yongin, Korea \\ ${ }^{6}$ Faculty of Built Environment and Engineering, Queensland University of Technology, Brisbane, Australia
}

\begin{abstract}
In this paper, different evaluation methods of Hot Spot Stresses (HSS) have been applied to four different welded structure details in order to compare them and to illustrate their differences. The HSSS at failure-critical locations were calculated by means of a series of finite element analyses. There was good overall agreement between calculated and experimentally determined HSS on the critical locations. While different methods and procedures exist for the computation of the structural hot-spot stress at welded joints, the recommendations within the International Institute of Welding (IIW) guideline concerning the 'Hot Spot Stress' approach were found to give good reference stress approximations for fatigue-loaded welded joints. This paper recommends and suggests an appropriate finite element modeling and hot spot stress evaluation technique based on round-robin stress analyses and experimental results of several welded structure details.
\end{abstract}

KEY WORDS: Hot-spot stress; Finite element method; Structural stress; Welded joint; International Institute of Welding (IIW).

\section{INTRODUCTION}

Many methods are available to predict the fatigue life of welded components. For this purpose, it is important to identify and consider the most commonly used stress definitions, which are the nominal stress, the structural hot spot stress and the local notch stress. Nominal stresses are those stresses derived from simple beam models or from Finite Element Method (FEM) based coarse mesh models. Stress concentrations resulting from gross shape of the structure are included in the nominal stress. The notch stress can be calculated by multiplying the hot spot stress by a stress concentration factor, the notch factor, $K_{w}$. The FEM can also be used to calculate the notch stress (Radaj, 1990). However, as the notch radii are small in size, the steep gradient of the stress evaluation curve leaves room for large errors. Consequently, a very fine mesh is necessary in finite element models (Petershagen, Fricke and Massel, 1991).

The structural hot spot stresses, also called geometric stresses, include nominal stresses and stresses from structural discontinuities and the presence of attachments, but do not include stresses due to the presence of welds. Due to the

Corresponding author: Jae-Myung Lee

e-mail:jaemlee@pusan.ac.kr difficulties in representing the singularities at the weld toe, finite element modeling cannot directly give the actual peak stress at the weld toe (Doerk, Fricke and Weissenborn, 2003; Fricke and Kahl, 2005). However, various types of stress extrapolation methods have been developed to overcome this problem (Hobbacher (Ed), 2009; Niemi (Ed), 1995; Dong, 2001; Dong, Hong and Cao, 2002; Xiao and Yamda, 2004).

Stresses that have been derived from fine mesh FEM models are geometric stresses. Effects caused by fabrication imperfections are not included in the FEM analyses, and must be accounted separately, e.g. misalignments of two welded parts. The greatest value of the extrapolation to the weld toe of the geometric stresses outside the region is called hot spot stress. This approach is typically used for fatigue-resistant design and/or the durability approval of welded offshore tubular joints and welded ship structures with various weld configurations. The size of the components involved makes it difficult, or expensive to determine their fatigue behavior and strength experimentally.

Most classification societies provide a method to determine structural stress but they may differ in many ways. A brief description of different methods of various classification societies and other code writing societies on how to calculate the structural stress is given next. DNV 
(2008) recommends that a 20-node solid elements with a size of $t / 2 \times t / 2$ or 8 -node shell elements with a size of $t \times t$ shall be used. Linear extrapolations of the component stresses from two points (t/2 and 3t/2) are conducted and the principal stresses are calculated at the hot spot.

Fricke and Petershagen and Paetzold (1998) recommend the use of 20-node solid elements that have a side length of the plate thickness at the hot spot. They also recommend at least three elements of equal length in the area where the stress increases. The stress is calculated at the upper side of the element from the stresses at the four integration points. Thereafter, a quadratic extrapolation of the component stress that is normal to the weld is obtained from the three elements. In this method, the consideration of the weld is given.

ABS (1992) recommends that 20-node solid elements or 8 -node shell elements are used with a size of $t \times t$. Linear extrapolation of the component stress from two points $(t / 2$ and $3 t / 2$ ) is conducted, and the maximum principal stress is used in the evaluation.

In Eurocode 9 (1998), the structural stress is defined as the greatest value of the component stress extrapolated in the normal direction to the weld. Shell or solid elements should be used for modelling the structure.

The recommendations of the International Institute of Welding (IIW) on fatigue of welded components and structures and on the effect of weld imperfections in respect to fatigue were first published in 1996. These recommendations were later updated in 2009 (Hobbacher (Ed), 2009). This code was established to cover all the current methods of verification, such as component testing, nominal stress, structural stress, and notch stress method. The main area that was updated in 2009 was the structural hot-spot stress concept. This allowed for an economic and coarser meshing in finite element analysis to be used.

A recent publication by Hobbacher (2009) provides a review of the updated procedure to determine a precise recommendation for FEA meshing for the structural hot spot stress method with an additional option for coarse meshing.

The study reported in this paper consists of two parts; a review of the current methodologies for Hot Spot Stress
Approach of welded structures according to IIW (Hobbacher (Ed), 2009), which also includes the numerical analyses using the finite element method to determine and validate the hotspot stress assessment procedures. In this review, several hot spot stress methods are briefly described and discussed in more detail. Emphasis is placed on welded plate structures being general guides for welded plate structures such as ship and offshore structures. A more comprehensive description of the approaches can be found in the current IIW (Hobbacher (Ed), 2009). The second part of this study is a round-robin study, which consists of two bending and tension tests of a typical welded joint detail as well as experimental measurement of HSSs. The results from the bending and tension tests are then compared with the results of the numerical stress analyses based on round-robin exercise.

\section{DETERMINATION OF STRUCTURAL HOT SPOT STRESSES ACCORDING TO IIW}

The structural hot spot stress can be determined using reference points and extrapolation to the weld toe at the hot spot in consideration. The method as defined here is limited to the assessment of the weld toe, i.e. cases shown in Fig.1 (a) to (e). It is not applicable to cases where crack will grow from the weld root and propagate through the weld metal, i.e. cases shown in Fig. 1 (f) to (i) (Hobbacher (Ed), 2009). An adequate design practice aims to overcome this kind of behaviour because the crack is not visible before it has propagated through the weld. Moreover, the structural stress methods cannot be directly applied to continuous welds subject to longitudinal loading. The nominal stress approach is suitable for such cases. In the case of a biaxial stress state at the plate surface, it is recommended to use the principal stress which is approximately perpendicular to the weld toe, i.e. within a deviation of $45^{\circ} \sim 90^{\circ}$. The other principal stress may be analysed, if necessary, using the fatigue class for parallel welds in the nominal stress approach.

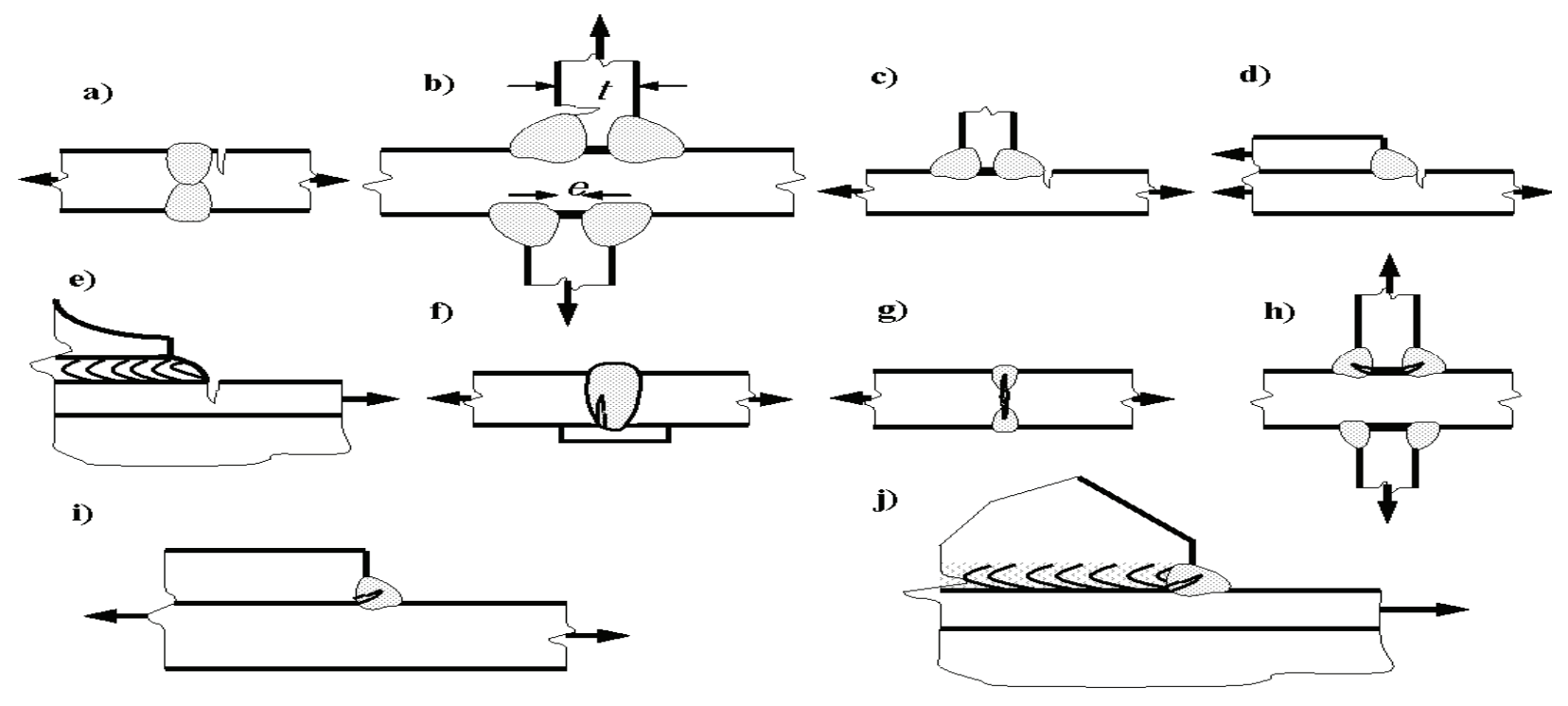

Fig. 1 Various locations of crack propagation in welded joints. 


\section{Types of Hot Spot Stress}

Generally the hot spot is the critical location at the weld toe where a fatigue crack can be expected to initiate. Hot spots can be identified into two types (Niemi, 1995) as shown in Fig. 2.

- For Type "A" the weld is located on a plate surface

- For Type "B" the weld is located on a plate edge

Fig. 1(a)-(d) show various weld details containing Type "A" hot spots at the weld on the plate surface. Fig. 3 shows typical details of containing Type " $\mathrm{B}$ " hot spots at the short weld toe or weld end on the plate edge. Geometrical notch effects in the vicinity of the welded joint have to be taken into account, as e.g. at plate edges, or unequal stress distribution by various reasons. Type " $\mathrm{A}$ " and " $\mathrm{B}$ " require different stress extrapolation points the latter not depending on the plate thickness. Therefore this study concentrates and focuses on Type "A" hot spot stress. The fatigue strength of these welded joint structures appears to be underestimated by the structural stress concentrations. Hence it is required to take a round joint shape and shelving corner radius.

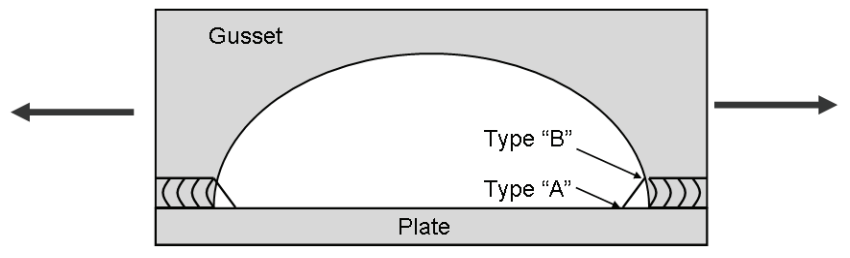

Fig. 2 Examples of hot spot types.

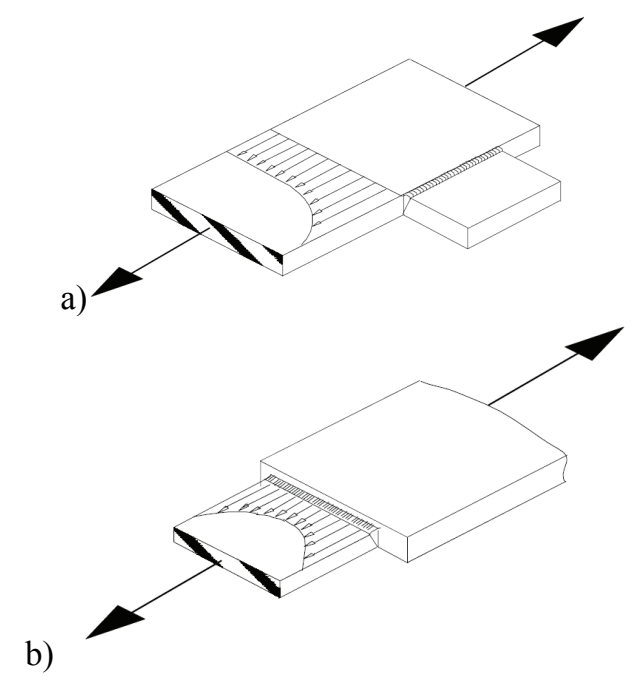

Fig. 3 A Typical type "B" hot spots at a plate edge.

\section{Definition of Type "A" of Structural Stress of HSS}

Usually, the hot spot is located at the weld toe. The hot spot stress is the value of the structural stress at the hot spot (Niemi, 1995). The distribution of structural stress $\left(\sigma_{\mathrm{s}}\right)$ through the plate thickness is usually the sum of membrane stress $\left(\sigma_{\mathrm{m}}\right)$ and shell bending stress $\left(\sigma_{\mathrm{b}}\right)$ as illustrated in Fig. 4. These stress distribution at welded joints of the plate is actually non-linear. However, these stresses are idealized as being linear as shown in Fig. 4. The stress components of this non-linear relationship can be separated into the membrane stress, shell-bending stress and non-linear peak stress $\left(\sigma_{\text {nlp }}\right)$, as shown in Fig. 5. Generally, the hot spot stresses account only for the overall geometry of the joint, and exclude local stress $\left(\sigma_{\mathrm{nlp}}\right)$ concentration effects (notch effects) due to the weld geometry discontinuities at the weld toe. The notch effects are included in the hot spot S-N curves based on experimental results.

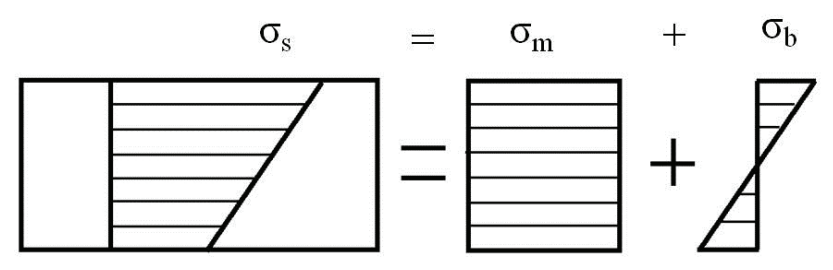

Fig. 4 Structural stresses comprising membrane and shell bending stresses.

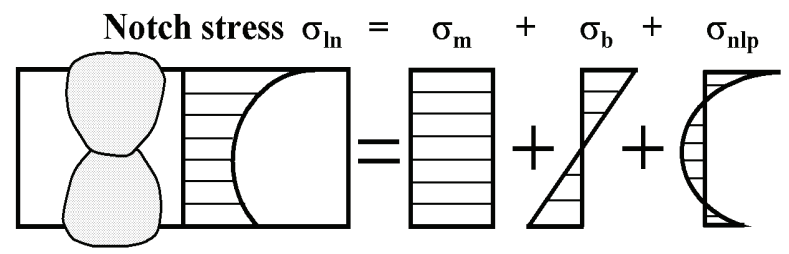

Fig. 5 Local notch stress distribution comprising membrane stress, shell bending stress and nonlinear peak stress.

\section{EXPERIMENTAL METHOD BASED ON IIW FOR THE DETERMINATION OF HOT SPOT STRESS}

\section{Determination of Hot Spot Stress Type "A"}

Fig. 6 shows how the structural stress distribution across plate thickness changes in the vicinity of a Type " $A$ " hot spot. At a distance of $0.4 t$ from the weld toe, the nonlinear component has practically vanished and the distribution is almost linear. This fact is exploited in the extrapolation technique used for approximation of the structural hot spot stress, as shown in Fig. 7.

In most Type "A" hot spots the structural stress and strain are linearly increased when approaching the weld toe. When the structural hot sport stress is determined using strain gauges, it is sufficient to use linear extrapolation, as shown in Fig. 7. Two strain gauges, $\mathrm{A}$ and $\mathrm{B}$, are attached $0.4 t$ and $1.0 t$ form the weld toe, and the structural strain at the hot spot is determined using linear extrapolation. In the field measurements from prototype testing, these extrapolation points give conservative results when compared to those recommended in conjunction with finite element analyses based on coarse mesh. 


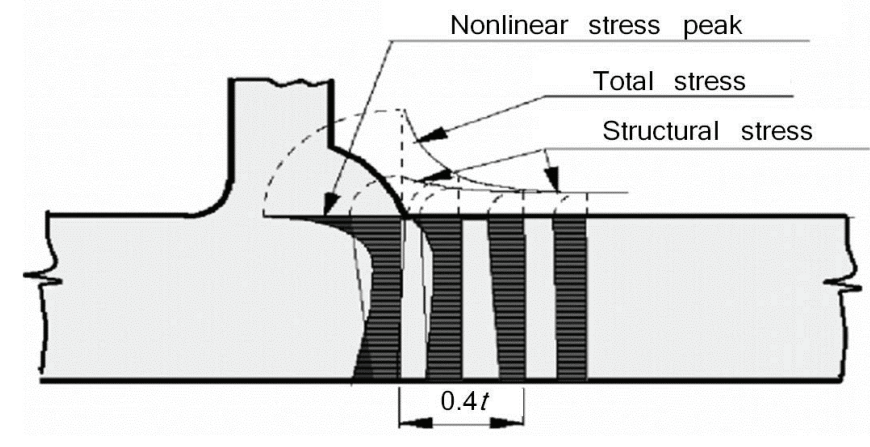

Fig. 6 Stress distributions across the plate thickness and along the surface in the vicinity of a weld toe.

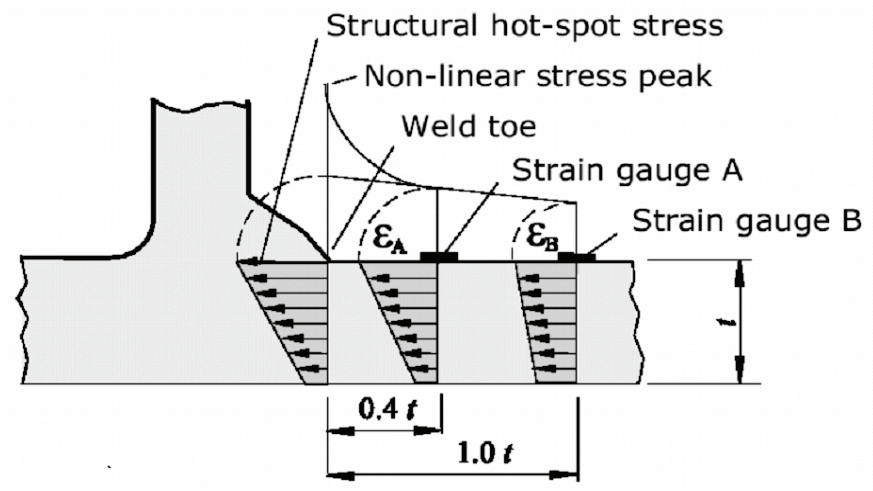

Fig. 7 Linear extrapolation of the measured strains to the weld toe in order to approximate the structural hot spot strain.

The recommended embedment and the number of strain gauges depend on the presence of higher shell bending stress, the wall thickness and the type of structural stress. The centre point of the first gauge should be at a distance of $0.4 t$ from the weld toe. The gauge length should not exceed $0.2 t$. If this is not possible due to a small plate-thickness, the leading edge of the gauge should be placed at a distance $0.3 t$ from the weld toe. The following extrapolation procedure and number of gauges are recommended:

When two gauges are used at reference points that are located at a distance of $0.4 t$ and $1.0 t$ from the weld toe, the estimated structural hot-spot strain based on linear extrapolation is calculated according to Eq. (1).

$\varepsilon_{\mathrm{HS}}=1.67 \varepsilon_{(0.4 t)}-0.67 \varepsilon_{(1.0 t)}$

The IIW recommendations for calculating the structural stress is to use the stresses from FEA or the strain from strain gauges at specified distances from the weld toe. The stresses or the strains are then extrapolated to the weld toe using a three point formula. In some cases where the stressed plate is resting on a relatively stiff elastic foundation, e.g., a beam flange just above a web plate, the stress in the vicinity of a structural discontinuity increases nonlinearly in the vicinity of the weld toe. In such cases, linear extrapolation would underestimate the actual structural hot spot stress. Instead, a quadratic extrapolation method is preferred. For this purpose, at least three strain gauges are required. It was recommended that they are attached at locations $0.4 t, 0.9 t$ and $1.4 t$ from the weld toe. Then the structural hot spot strain is given by:

$\varepsilon_{\mathrm{HS}}=2.52 \varepsilon_{(0.4 t)}-2.24 \varepsilon_{(0.9 t)}+0.72 \varepsilon_{(1.4 t)}$

\section{Calculation of Hot Spot Stress Type "A"}

Due to some limitations of the experimental observations, multi-element strip strain gauges with fixed distances between the gauges are occasionally used. Thus, their positions may not be located as recommended above. In such circumstances, it was recommended that sufficient gauges should be used to enable a curve to be fitted to the results to establish the required strains by interpolation. If the stress state is similar to a uni-axial state, the structural hot spot stress can be approximated by using the following equation.

$\sigma_{\mathrm{HS}}=\mathrm{E} \varepsilon_{\mathrm{HS}}$

However, if the stress state is bi-axial, the actual stress may be up to $10 \%$ higher than that obtained from Eq. (3). If a higher accuracy is required, the ratio of the longitudinal and transverse strains should be established from rosette strain gauges or FEA. The structural hot spot stress $\left(\sigma_{\mathrm{HS}}\right)$ can be calculated (assuming that the principal stress is transverse to the weld toe) from Eq. 4.

$\sigma_{H S}=E \varepsilon_{x} \frac{1+v\left(\varepsilon_{y} / \varepsilon_{x}\right)}{1-v^{2}}$

Instead of absolute strains, strain ranges are usually measured and then substituted into Eq. (4), producing the range of structural hot spot stress $\left(\Delta \sigma_{\mathrm{HS}}\right)$.

\section{FEA METHODS FOR THE DETERMINATION OF HOT SPOT STRESS}

In the design phase, finite element analysis is an ideal tool for determining the structural hot spot stress. Linear elastic material behaviour is commonly assumed since the structural hot spot stress range should not exceed twice the yield strength of the material. Since the structural stress range is required, at least two loading cases should normally be analyzed, giving the maximum and minimum stresses. Either shell or solid elements can be used but the element mesh should be designed carefully so that extrapolation of the stresses to weld toe can be performed along the most critical extrapolation path. Care must be taken to avoid misinterpreting the finite element results. For example:

- A typical post-processor displays the nodal stress at the weld toe as an average of two elements located on both sides of the weld toe. It is advisable to use 
post-processing only for the elements of interest in front of the weld.

- One must obtain results, which exclude the nonlinear peak stresses even in sections close to the weld toe. This is the case corresponding to the use of shell elements. If a single-layer solid element mesh is used, a linear distribution is obtained with 8-node elements or with reduced integration in thickness direction in the case of 20-node elements. If multilayer solid element mesh is used, the results include a more or less accurate approximation of the nonlinear stress distribution. The linearly distributed part, or the structural hot spot stress can then be resolved only by dividing the distribution in three parts according to Fig. 5.

In the finite element analysis of large structures, it is not practical to use a fine mesh required to accurately resolve the stress field in the vicinity of the weld toe. A practical, relatively coarse mesh with a typical element size of $t \times t$ for Type "A" hot spots can normally be used, probably in connection with the sub-modelling technique. As the weld toe is modeled as a sharp notch, the singularity effect may increase the stresses in the first element at $0.5 t$. This compensates the error in extrapolation, caused by relatively distant extrapolation.

\section{Calculation of Structural Hot Spot Stress}

\section{Shell (plate) finite element model}

The elements have to be arranged in the mid-plane of the structural components as shown in Fig. 8 (a). Eight-noded element is recommended, particularly in the case of steep stress gradients. In simplified models, the welds are not modeled, except for the cases where the results are affected by local bending, e.g. due to an offset between plates or due to the small distance between adjacent welds. Here the welds may be included by vertical or inclined plate elements having appropriate stiffness or by introducing constraint equations or rigid links to couple node displacements.

\section{Solid finite element model}

An alternative method of using prismatic solid elements is recommended, particularly for complex cases. This can be supported by 20 -node is oparametric elements with mid-side nodes at the edges, which allow only one element to be arranged in the plate thickness direction due to the quadratic displacement function and the linear stress distribution. It is also using solid element allowing the weld to be easily modeled with prism atic elements. By the adoption of reduced integration, the stresses can be directly extrapolated from the integration points to the element surface and subsequently to the weld toe. Modeling of welds was generally recommended as shown in Fig. 8 (b).

Appropriate element widths are important particularly in cases with steep stress gradients. The width of the solid elements in front of the attachment should not exceed the attachment width 'w', i. e. the attachment thickness plus two weld leg lengths (Hobbacher (Ed), 2009).

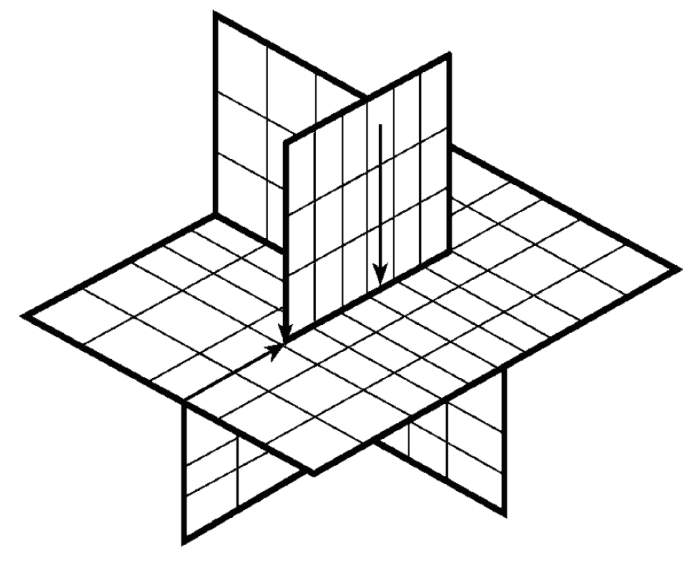

(a) Shell Elements.

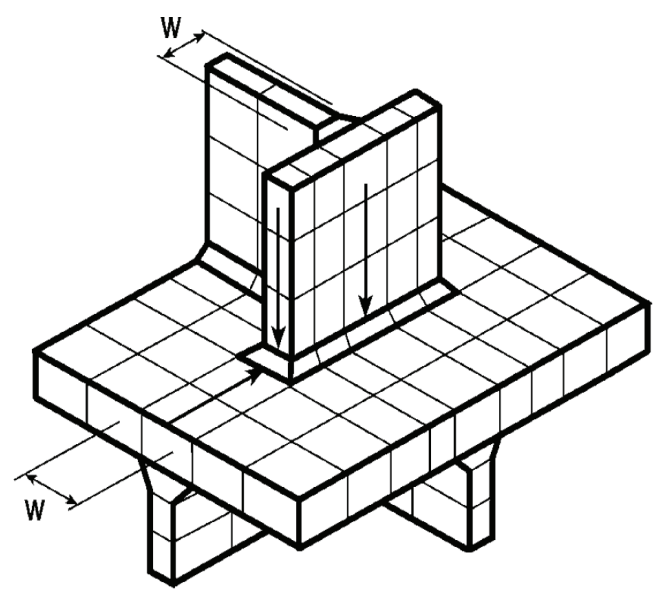

(b) Solid Elements ( $w=$ attachment width).

Fig. 8 Typical meshes and stress evaluation paths for a welded detail.

\section{Relatively Fine Meshes}

Using fine meshing subject to Type "A" can be defined as follows:

- In the case of high stress gradient in the vicinity of hot spot

- Using 4-node shell or 8-node solid elements

- To analyze the thick plate structures

Linear extrapolation method is based on principal stresses from two nodes on the surface at $0.4 t$ and $1.0 t$ from the weld toe, where $t$ is the thickness of stressed plate (Hobbacher (Ed), 2009).. Estimated structural hot-spot stress based on linear extrapolation is calculated based on the following equation:

$\sigma_{\mathrm{HS}}=1.67 \sigma(0.4 t)-0.67 \sigma(1.0 t)$

$\sigma_{\mathrm{HS}}=2.52 \sigma(0.4 t)-2.24 \sigma(0.9 t)+0.72 \sigma(1.4 t)$ 
Three extrapolation points at $0.4 t, 0.9 t$ and $1.4 t$ are considered in the estimation of structural hot-spot stress at the weld toe. The hot-spot stress is computed based on the following relationship (Hobbacher (Ed), 2009).

It was recommended to directly read the stresses at node using Eqs. (5) or (6). The first and second elements should be $0.4 t$ and $0.6 t$ long along the loading direction according to $\mathrm{Eq}$ (5). For such cases, the first, second and third elements should be $0.4 t, 0.5 t$ and $0.5 t$ long using Eq. (6). In the case of approach to the vicinity of discontinuity with 4-node shell and 8-node solid elements, it needs to define the elements in more detail.

\section{Relatively Coarse Meshes}

Two extrapolation points at distances $0.5 t$ and $1.5 t$ in front of the weld toe are considered in this method based on thickness (Fricke, 2002). Thickness effect is also considered in this method. The structural hot-spot stress is estimated using the following equation.

$\sigma_{\mathrm{HS}}=1.5 \sigma(0.5 t)-0.5 \sigma(1.5 t)$

Eq. (7) is generally recommended for coarser meshes where element length at the weld toe region is equal to the plate thickness. Generally, this method is used in the ship building industry.
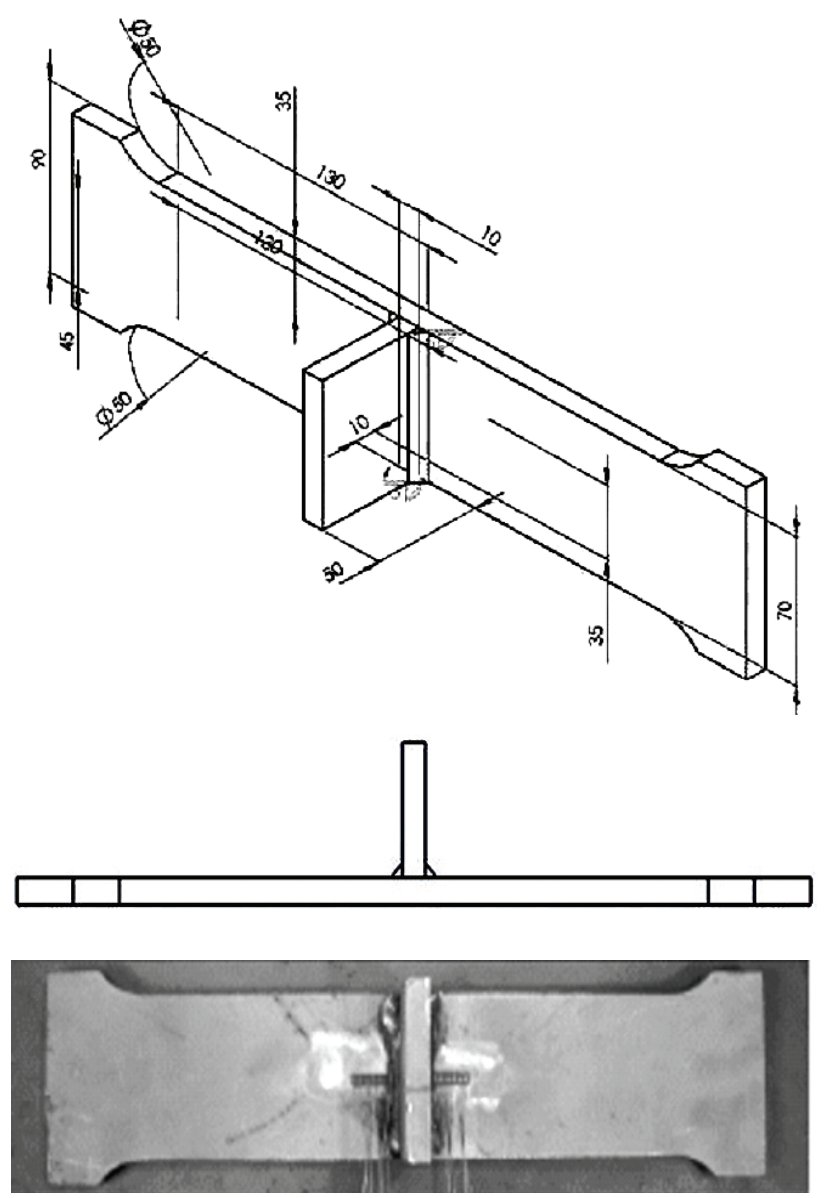

(a) Type 1.

\section{HSS ROUND-ROBIN STUDY}

Within a joint study of The Korean Weld Joining Society, four structural details were investigated in a round-robin study by using different finite element programs and modeling techniques. All of the details are shown here to illustrate the scatter of the analysis results. In addition, this study has presented the details of an experimental study undertaken to investigate two types of standard specimens (Type "A") for hot spot stress evaluation.

The exercise in this study was independently performed by four organizations without any information exchange.

The aim of this round robin study was to elucidate the discrepancies according to the different methods, which were used by each participant. The independent participants used predefined method to evaluate the stress and strain by using their own selected finite element analysis code (ANSYS, 2006; HKS (ABAQUS), 2007; I-DEAS, 1993). For comparative study, experimental measurements were taken by only one participant. It is noted that the experimental conditions as well as specimen details were used by all the participants in the same manner.
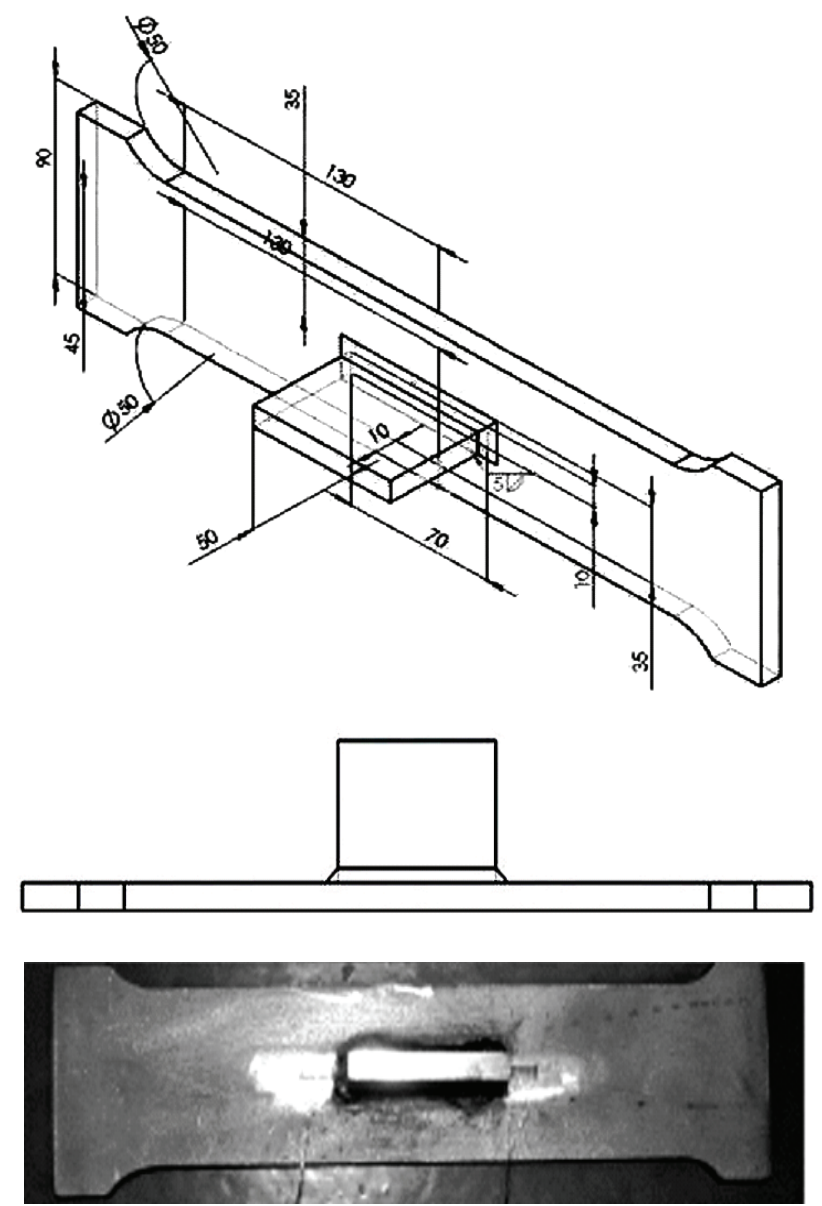

(b) Type 2.

Fig. 9 Geometries of the non-load carrying welded specimens. 


\section{Experimental Setup}

The dimension of the test specimen is shown in Fig. 9. The steel plates of thickness of both $10 \mathrm{~mm}$ are used as the thickness of the main plate of test specimens. The gusset plate dimension for both Type 1 and Type 2, indicated as height $(50 \mathrm{~mm})$ and width $(70 \mathrm{~mm})$, are kept identical for specimens.

The material used in this test is a ship-structural mild steel of grade-A. The design yield stress of the material is defined as $235 \mathrm{MPa}$ for ship-structural mild steel according to the specifications of classification societies.

Flux Cored Arc Welding (FCAW) is used to attach the gusset plate into the base plate. Gusset plate and main plate are welded by three passes under flat position. Moldings reflecting the weld bead shapes are obtained using dental silicon rubber and sliced into $2 \mathrm{~mm}$ thickness to obtain leg lengths of both base plate and the gusset plate sides. Average leg lengths of the base plate and the gusset sides are $5.0 \mathrm{~mm}$, respectively.

Fig. 10 shows the typical placement of strain gauges. The strain gauges near the weld toe are placed either $4 \mathrm{~mm}(0.4 t)$ in distance from the toe. The remaining strain gauges are attached $10 \mathrm{~mm}(1.0 t)$ for Type 2.

Fig. 11 and Fig. 12 show a sample photo for bending and tension tests. Experimental studies were conducted using a three-point bending arrangement to simulate a $6.86 \mathrm{kN}$ for bending point load, and a $29.4 k N$ for tension in the test specimen at the loading points.

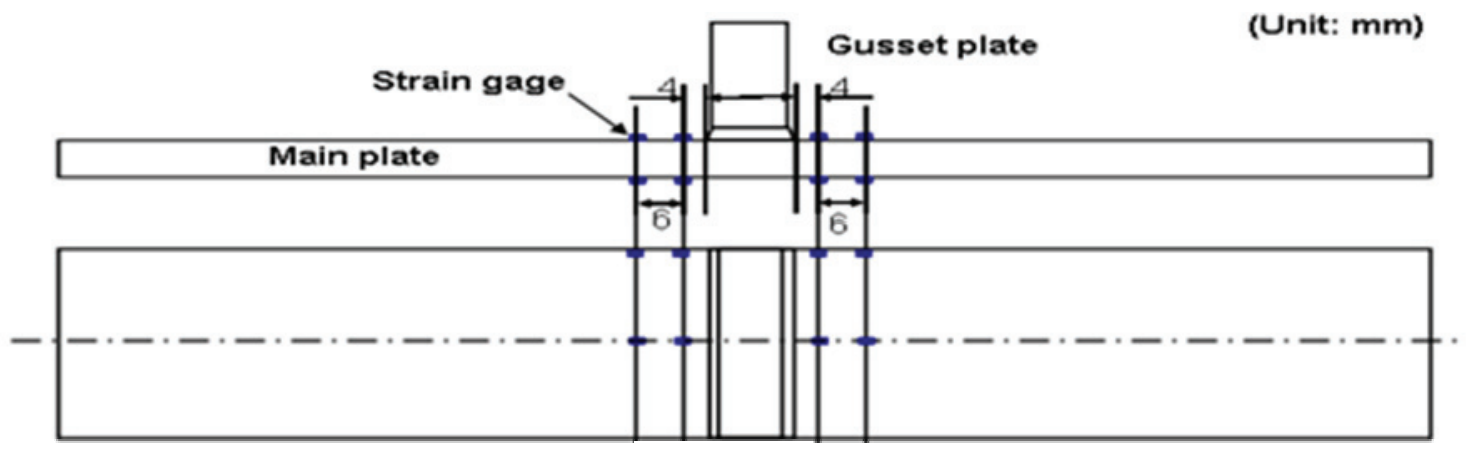

(a) Type 1.

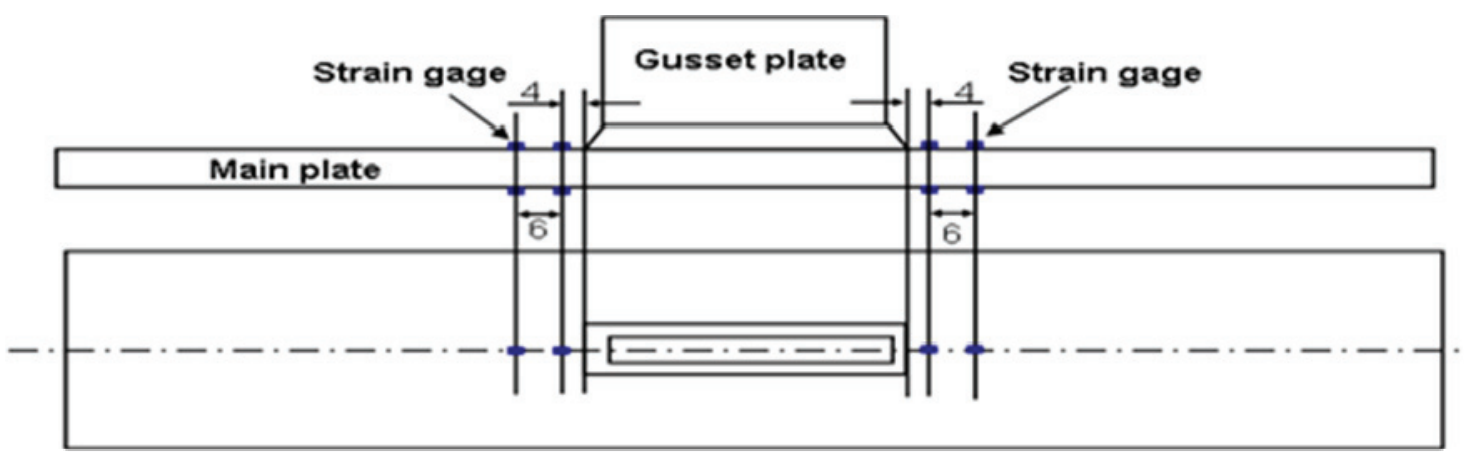

(b) Type 2 .

Fig. 10 Strain gauges locations in test specimens.
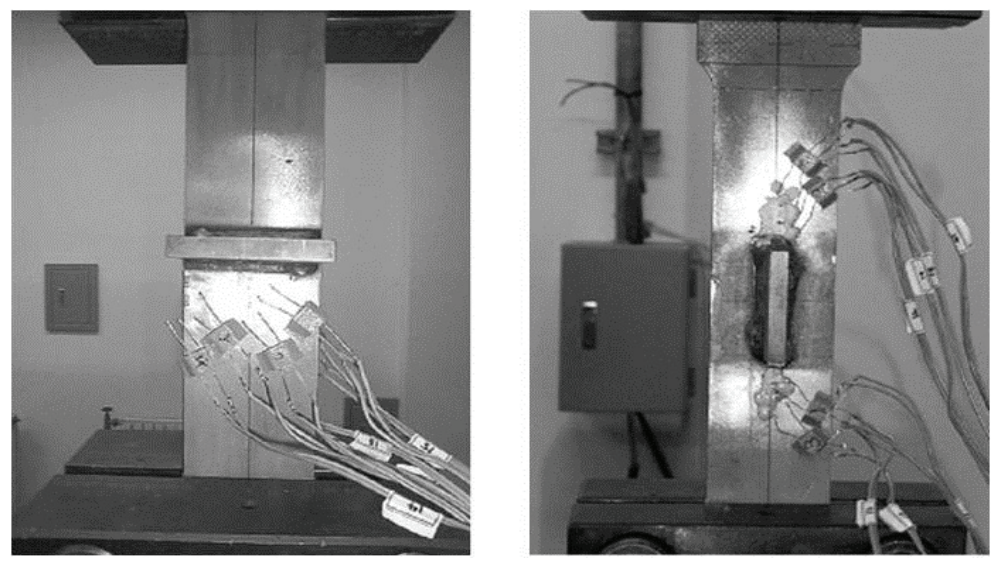

Fig. 11 Tensile tests of standard specimens (left: transverse gusset, right: longitudinal gusset). 


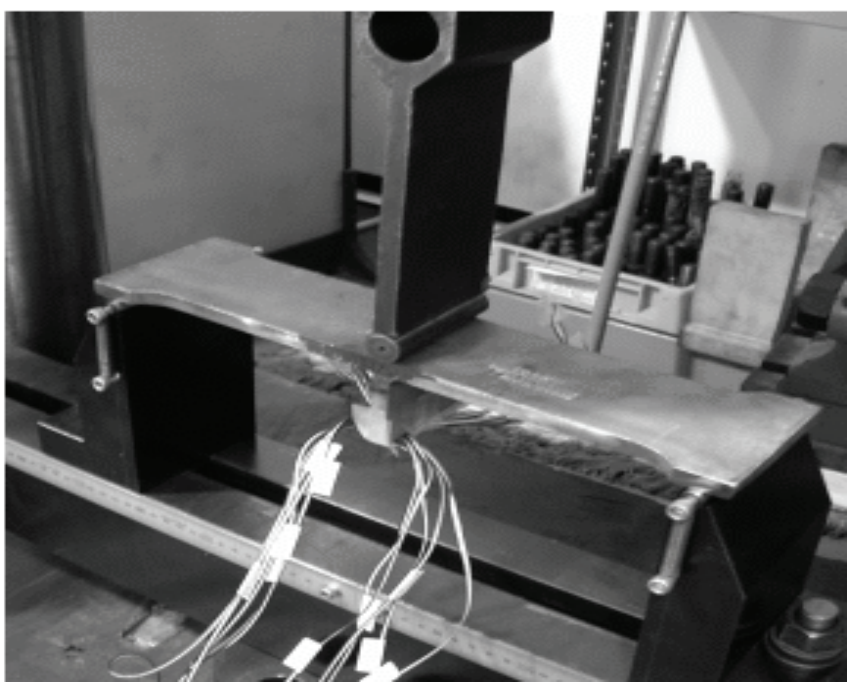

(a) Transverse gusset.

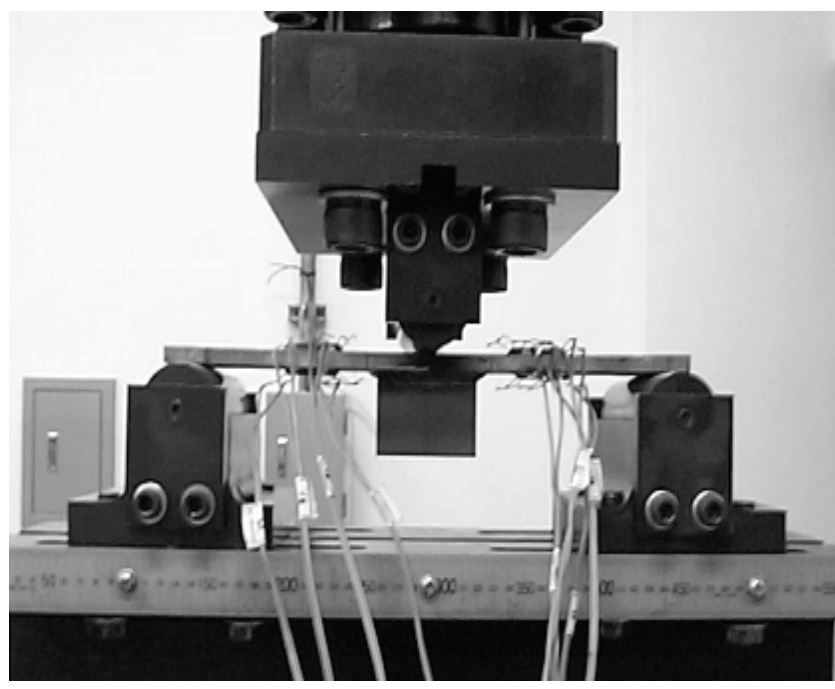

(b) Longitudinal gusset.

Fig. 12 Bending test of standard specimen.

\section{Results of Round Robin Study}

Fig. 13 presents the details of the finite element codes, type of elements, typical modeling and extrapolation rules for each participant. Tables 1 to 4 give the hot spot stress results with various details of weldment effect, elements size and extrapolations. Details of comparison with experimental results are also summarized in these tables.

As shown in Table 1, it is found that the linear and quadratic extrapolation method underestimates both the hot

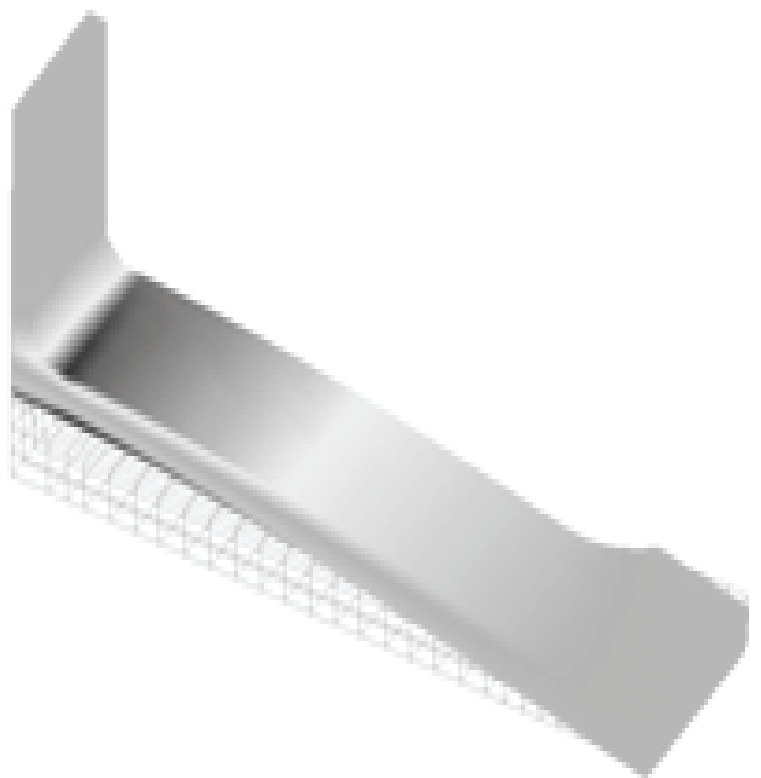

(a) Type 1-solid. spot stress of bending and tension loadings for Type I. The tension loading has been underestimated by $16.4 \%$ with a coefficient of variation (COV) of 0.093 using the linear method whilst $15.0 \%$ with a COV of 0.109 using the quadratic method in comparison with experimental and FEA results. Similarly, as shown in Table 2, the linear and quadratic extrapolation methods subjected to bending loading underestimates the hot spot stress by $9.9 \%$ with a COV of 0.445 using the linear method and $16.0 \%$ with a COV of 0.109 using the quadratic method.

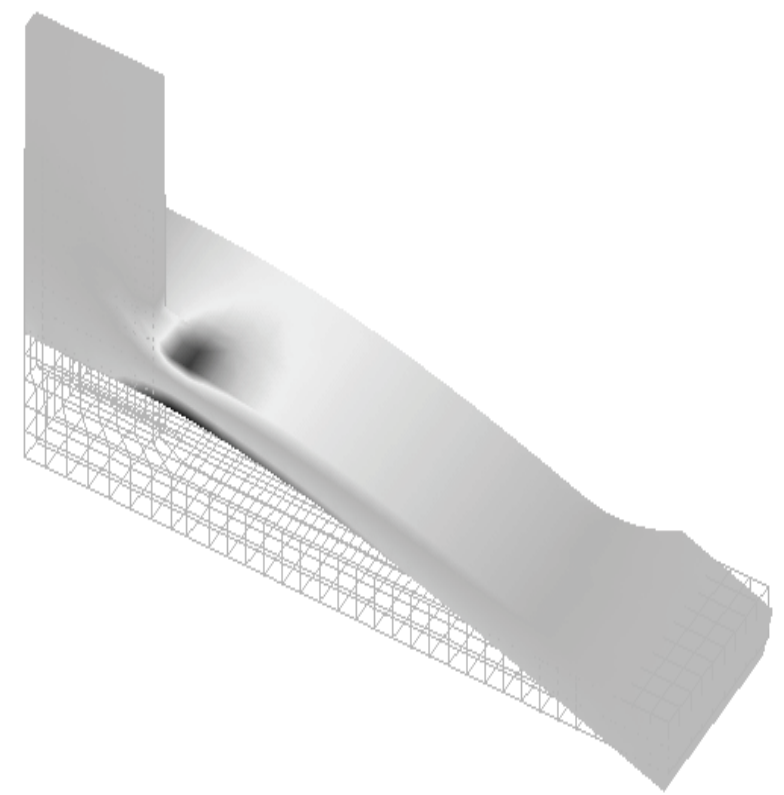

(b) Type 2-solid.

Fig. 13a Finite element mesh of a typical model using I-DEAS. 


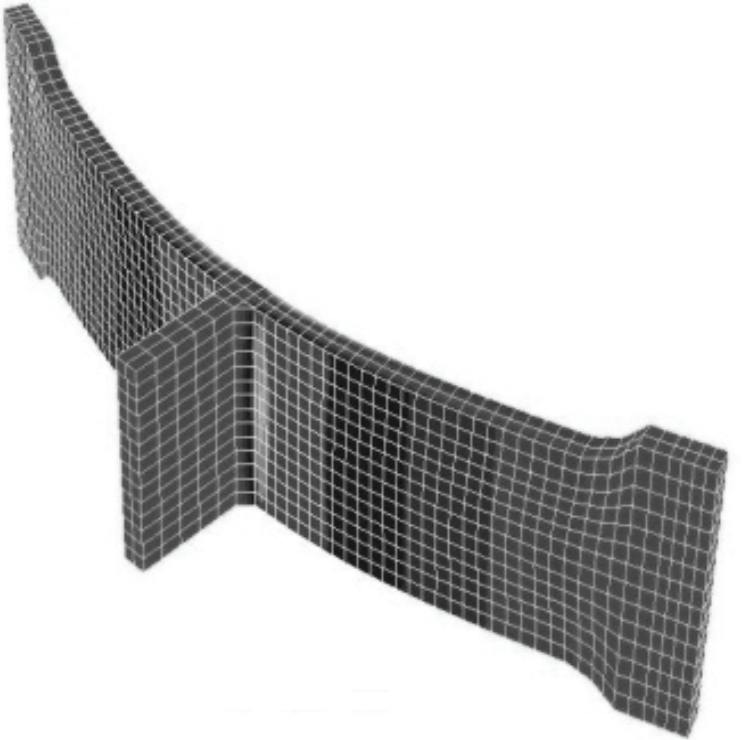

(a) Type 1-solid.

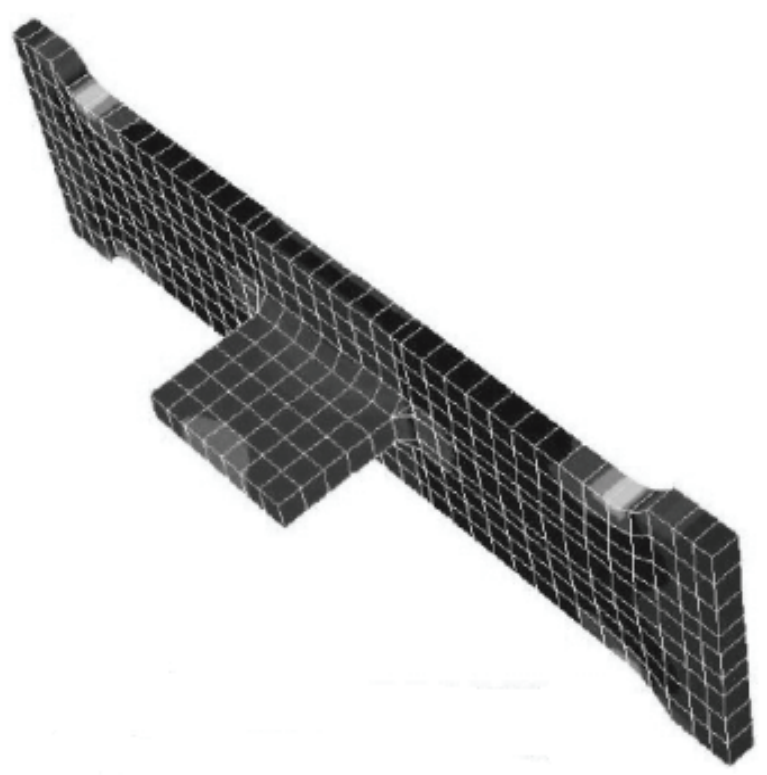

(b) Type 2-solid.

Fig. 13b Finite element mesh of a typical model using ABAQUS.

In Table 3, it can be found that the linear extrapolation methods subjected to tension loading underestimates the hot spot stress by $2.0 \%$ with a COV of 0.180 in comparison with experimental and FEA results for Type II. However, quadratic extrapolation methods slightly overestimate the hot spot stress by $1.0 \%$ with a COV 0.183 .

Table 4 shows an underestimation of the hot spot stress for bending loading by $14.4 \%$ with a COV of 0.485 using the linear method and $15.7 \%$ with a COV of 0.483 using the quadratic extrapolation when compared with experimental and FEA results for Type II. This comparison was made based on the experimentally measured stresses in the same manner.

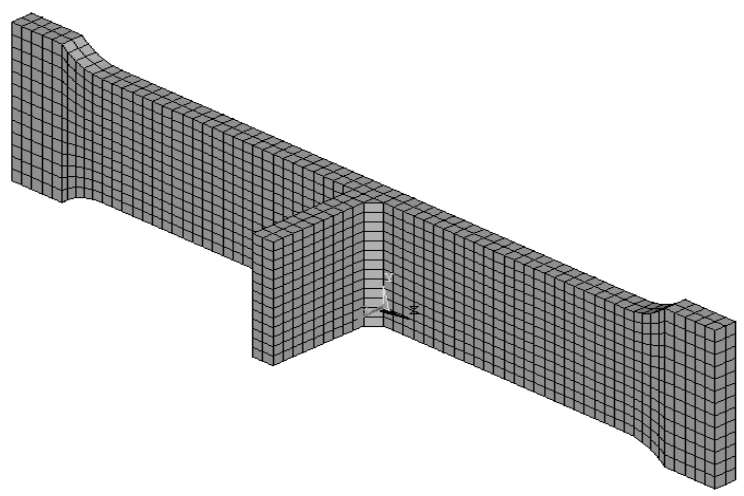

(a) Type 1-solid.

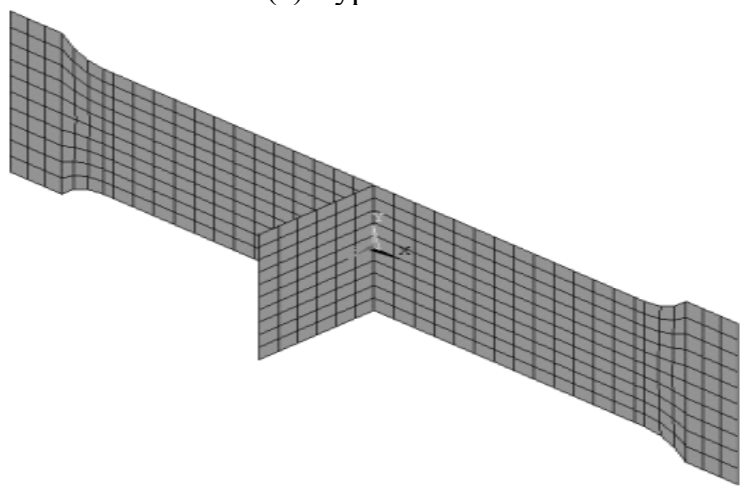

(b) Type 1-shell.

Fig. 13c Finite element mesh of a typical model using ANSYS.

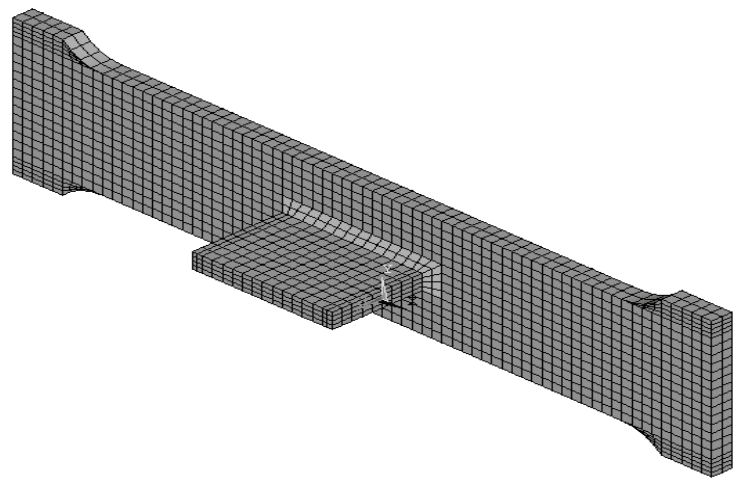

(a) Type 2-solid.

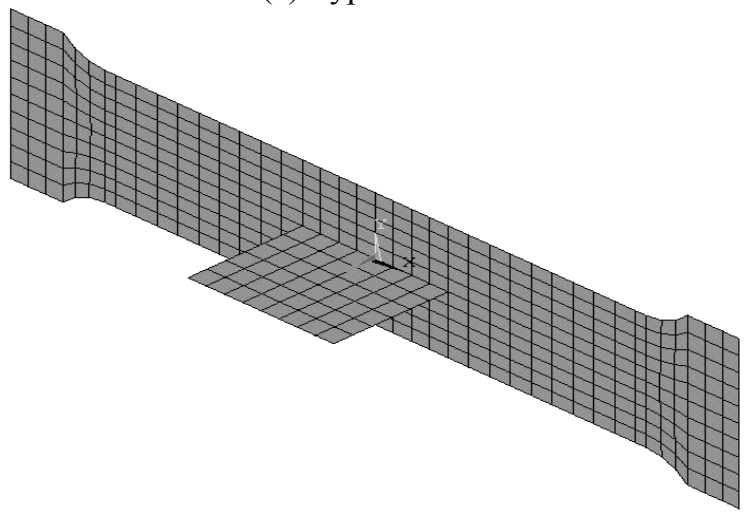

(b) Type 2-shell.

Fig. 13d Finite element mesh of a typical model using ANSYS. 
Table 1 Hot spot stress results of type 1 subject to tension.

\begin{tabular}{|c|c|c|c|c|c|c|c|c|}
\hline \multirow{3}{*}{$\begin{array}{c}\text { FEA } \\
\text { model }\end{array}$} & \multirow{3}{*}{ Mesh } & \multirow{2}{*}{\multicolumn{2}{|c|}{ Element }} & \multirow{3}{*}{ Size } & \multirow{3}{*}{$\begin{array}{l}\text { Weld } \\
\text { effect } \\
\text { (Bead } \\
\text { shape) }\end{array}$} & \multicolumn{3}{|c|}{$\begin{array}{l}\text { HSS by Extrapolation } \\
\text { method }\end{array}$} \\
\hline & & & & & & \multicolumn{2}{|c|}{ FEA $(M P a)$} & \multirow{2}{*}{$\begin{array}{l}\text { Exp. } \\
(M P a) \\
\text { Linear }\end{array}$} \\
\hline & & Shell & Solid & & & Linear & Quad. & \\
\hline T1-1 & $\mathrm{F}$ & 4node & - & $0.5(\mathrm{t} \times \mathrm{t})$ & No & 41.96 & 41.93 & 52.34 \\
\hline $\mathrm{T} 1-2$ & $\mathrm{~F}$ & 8node & - & $0.5(t \times t)$ & No & 41.95 & 41.92 & 52.34 \\
\hline T1-3 & $\mathrm{F}$ & 4node & - & $0.5(\mathrm{t} \times \mathrm{t})$ & Yes & 41.79 & 41.69 & 52.34 \\
\hline T1-4 & $\mathrm{F}$ & 8node & - & $0.5(\mathrm{t} \times \mathrm{t})$ & Yes & 41.79 & 41.99 & 52.34 \\
\hline T1-5 & $\mathrm{F}$ & - & 8node & $0.5(\mathrm{t} \times \mathrm{t})$ & Yes & 45.13 & 45.62 & 52.34 \\
\hline T1-6 & $\mathrm{F}$ & - & 20node & $0.5(\mathrm{t} \times \mathrm{t})$ & Yes & 43.56 & 43.56 & 52.34 \\
\hline T1-7 & $\mathrm{C}$ & - & 20node & $t \times t$ & Yes & 49.64 & - & 52.34 \\
\hline T1-8 & $\mathrm{F}$ & - & 20node & $0.5(\mathrm{t} \times \mathrm{t})$ & Yes & 56.38 & - & 52.34 \\
\hline T1-9 & $\mathrm{C}$ & - & 20node & $t \times t$ & Yes & - & 50.90 & 52.34 \\
\hline T1-10 & $\mathrm{F}$ & - & 20node & $0.5(\mathrm{t} \times \mathrm{t})$ & Yes & - & 58.87 & 52.34 \\
\hline T1-11 & $\mathrm{F}$ & 4node & & $0.5(\mathrm{t} \times \mathrm{t})$ & No & 41.96 & 41.93 & 52.34 \\
\hline T1-12 & $\mathrm{F}$ & 8node & & $0.5(\mathrm{t} \times \mathrm{t})$ & No & 41.95 & 41.92 & 52.34 \\
\hline T1-13 & $\mathrm{F}$ & 4node & & $0.5(t \times t)$ & Yes & 41.79 & 41.69 & 52.34 \\
\hline T1-14 & $\mathrm{F}$ & 8node & & $0.5(\mathrm{t} \times \mathrm{t})$ & Yes & 41.79 & 41.99 & 52.34 \\
\hline T1-15 & $\mathrm{F}$ & - & 8node & $0.5(\mathrm{t} \times \mathrm{t})$ & Yes & 45.13 & 45.62 & 52.34 \\
\hline T1-16 & $\mathrm{F}$ & - & 20node & $0.5(\mathrm{t} \times \mathrm{t})$ & Yes & 43.56 & 43.56 & 52.34 \\
\hline
\end{tabular}

Notes: $\mathrm{F}=$ fine mesh; $\mathrm{C}=$ coarse mesh

Table 2 Hot spot stress results of type 1 subject to bending.

\begin{tabular}{|c|c|c|c|c|c|c|c|c|}
\hline \multirow{3}{*}{$\begin{array}{l}\text { FEA } \\
\text { model }\end{array}$} & \multirow{3}{*}{ Mesh } & \multirow{2}{*}{\multicolumn{2}{|c|}{ Element }} & \multirow{3}{*}{ Size } & \multirow{3}{*}{$\begin{array}{l}\text { Weld } \\
\text { effect } \\
\text { (Bead } \\
\text { shape) }\end{array}$} & \multicolumn{3}{|c|}{$\begin{array}{c}\text { HSS by Extrapolation } \\
\text { method }\end{array}$} \\
\hline & & & & & & \multicolumn{2}{|c|}{ FEA $(M P a)$} & Exp. \\
\hline & & Shell & Solid & & & Linear & Quad. & Linear \\
\hline T1-17 & $\mathrm{F}$ & 4node & - & $0.5(\mathrm{t} \times \mathrm{t})$ & No & 218.66 & 214.25 & 410.55 \\
\hline T1-18 & $\mathrm{F}$ & 8node & - & $0.5(\mathrm{t} \times \mathrm{t})$ & No & 228.77 & 226.12 & 410.55 \\
\hline T1-19 & $\mathrm{F}$ & 4node & - & $0.5(t \times t)$ & Yes & 212.88 & 211.11 & 410.55 \\
\hline T1-20 & $\mathrm{F}$ & 8node & - & $0.5(\mathrm{t} \times \mathrm{t})$ & Yes & 220.43 & 218.57 & 410.55 \\
\hline T1-21 & $\mathrm{F}$ & - & 8node & $0.5(\mathrm{t} \times \mathrm{t})$ & Yes & 510.81 & 522.28 & 410.55 \\
\hline T1-22 & $\mathrm{F}$ & - & 20node & $0.5(\mathrm{t} \times \mathrm{t})$ & Yes & 476.37 & 479.91 & 410.55 \\
\hline $\mathrm{T} 1-23$ & $\mathrm{C}$ & - & 20node & $t \times t$ & Yes & 534.16 & - & 410.55 \\
\hline T1-24 & $\mathrm{F}$ & - & 20node & $0.5(\mathrm{t} \times \mathrm{t})$ & Yes & 582.25 & - & 410.55 \\
\hline T1-25 & $\mathrm{C}$ & - & 20node & $\mathrm{t} \times \mathrm{t}$ & Yes & - & 506.93 & 410.55 \\
\hline T1-26 & $\mathrm{F}$ & - & 20node & $0.5(\mathrm{t} \times \mathrm{t})$ & Yes & - & 549.16 & 410.55 \\
\hline
\end{tabular}

Notes: $\mathrm{F}=$ fine mesh; $\mathrm{C}=$ coarse mesh

\section{CONCLUDING REMARKS}

Currently, maximum efforts are given for the accurate determination of reference stresses in complex welded structures
Table 3 Hot spot stress results of type 2 subject to tension.

\begin{tabular}{|c|c|c|c|c|c|c|c|c|}
\hline \multirow{3}{*}{$\begin{array}{l}\text { FEA } \\
\text { model }\end{array}$} & \multirow{3}{*}{ Mesh } & \multirow{2}{*}{\multicolumn{2}{|c|}{ Element }} & \multirow{3}{*}{ Size } & \multirow{3}{*}{$\begin{array}{l}\text { Weld } \\
\text { effect } \\
\text { (Bead } \\
\text { shape) }\end{array}$} & \multicolumn{3}{|c|}{$\begin{array}{l}\text { HSS by Extrapolation } \\
\text { method }\end{array}$} \\
\hline & & & & & & \multicolumn{2}{|c|}{ FEA $(M P a)$} & \multirow{2}{*}{$\begin{array}{c}\text { Exp. } \\
(M P a) \\
\text { Linear }\end{array}$} \\
\hline & & Shell & Solid & & & Linear & Quad. & \\
\hline T2-1 & $\mathrm{F}$ & 4node & - & $0.5(t \times t)$ & No & 76.71 & 79.07 & 60.38 \\
\hline $\mathrm{T} 2-2$ & $\mathrm{~F}$ & 8node & - & $0.5(\mathrm{t} \times \mathrm{t})$ & No & 70.63 & 71.71 & 60.38 \\
\hline $\mathrm{T} 2-3$ & $\mathrm{~F}$ & 4node & - & $0.5(\mathrm{t} \times \mathrm{t})$ & Yes & 73.97 & 76.03 & 60.38 \\
\hline $\mathrm{T} 2-4$ & $\mathrm{~F}$ & 8node & - & $0.5(\mathrm{t} \times \mathrm{t})$ & Yes & 77.99 & 81.23 & 60.38 \\
\hline $\mathrm{T} 2-5$ & $\mathrm{~F}$ & - & 8node & $0.5(\mathrm{t} \times \mathrm{t})$ & Yes & 60.04 & 62.49 & 60.38 \\
\hline $\mathrm{T} 2-6$ & $\mathrm{~F}$ & - & 20node & $0.5(\mathrm{t} \times \mathrm{t})$ & Yes & 55.92 & 57.49 & 60.38 \\
\hline $\mathrm{T} 2-7$ & $\mathrm{C}$ & - & 20node & $t \times t$ & Yes & 44.59 & - & 60.38 \\
\hline $\mathrm{T} 2-8$ & $\mathrm{~F}$ & - & 20node & $0.5(\mathrm{t} \times \mathrm{t})$ & Yes & 46.19 & - & 60.38 \\
\hline T2-9 & $\mathrm{C}$ & - & 20node & $t \times t$ & Yes & - & 45.45 & 60.38 \\
\hline $\mathrm{T} 2-10$ & $\mathrm{~F}$ & - & 20node & $0.5(\mathrm{t} \times \mathrm{t})$ & Yes & - & 47.17 & 60.38 \\
\hline $\mathrm{T} 2-11$ & $\mathrm{C}$ & - & 20node & $t \times t$ & es & 56.41 & 58.66 & 60.38 \\
\hline $\mathrm{T} 2-12$ & $\mathrm{~F}$ & - & 8node & $0.5(\mathrm{t} \times \mathrm{t})$ & Yes & 56.41 & 58.76 & 60.38 \\
\hline $\mathrm{T} 2-13$ & $\mathrm{~F}$ & - & 20node & $0.5(\mathrm{t} \times \mathrm{t})$ & Yes & 54.74 & 56.80 & 60.38 \\
\hline T2-14 & $\mathrm{C}$ & 4node & - & $t \times t$ & No & 52.39 & 52.78 & 60.38 \\
\hline T2-15 & $\mathrm{F}$ & 4node & - & $0.5(\mathrm{t} \times \mathrm{t})$ & No & 52.97 & 54.74 & 60.38 \\
\hline T2-16 & $\mathrm{C}$ & 8node & - & $t \times t$ & No & 57.58 & 60.14 & 60.38 \\
\hline T2-17 & $\mathrm{F}$ & 8node & - & $0.5(t \times t)$ & No & 50.72 & 51.80 & 60.38 \\
\hline
\end{tabular}

Notes: $\mathrm{F}=$ fine mesh; $\mathrm{C}=$ coarse mesh

Table 4 Hot spot stress results of type 2 subject to bending.

\begin{tabular}{|c|c|c|c|c|c|c|c|c|}
\hline \multirow{3}{*}{$\begin{array}{l}\text { FEA } \\
\text { model }\end{array}$} & \multirow{3}{*}{ Mesh } & \multirow{2}{*}{\multicolumn{2}{|c|}{ Element }} & \multirow{3}{*}{ Size } & \multirow{3}{*}{$\begin{array}{l}\text { Weld } \\
\text { effect } \\
\text { (Bead } \\
\text { shape) }\end{array}$} & \multicolumn{3}{|c|}{$\begin{array}{c}\text { HSS by Extrapolation } \\
\text { method }\end{array}$} \\
\hline & & & & & & \multicolumn{2}{|c|}{ FEA $(M P a)$} & Exp. \\
\hline & & Shell & Solid & & & Linear & Quad. & Linear \\
\hline T2-18 & $\mathrm{F}$ & 4node & - & $0.5(\mathrm{t} \times \mathrm{t})$ & No & 230.14 & 245.54 & 435.04 \\
\hline T2-19 & $\mathrm{F}$ & 8node & - & $0.5(t \times t)$ & No & 194.73 & 201.50 & 435.04 \\
\hline $\mathrm{T} 2-20$ & $\mathrm{~F}$ & 4node & - & $0.5(\mathrm{t} \times \mathrm{t})$ & Yes & 192.77 & 203.07 & 435.04 \\
\hline $\mathrm{T} 2-21$ & $\mathrm{~F}$ & 8node & - & $0.5(\mathrm{t} \times \mathrm{t})$ & Yes & 176.97 & 186.68 & 435.04 \\
\hline $\mathrm{T} 2-22$ & $\mathrm{~F}$ & - & 8node & $0.5(\mathrm{t} \times \mathrm{t})$ & Yes & 564.37 & 601.16 & 435.04 \\
\hline $\mathrm{T} 2-23$ & $\mathrm{~F}$ & - & 20node & $0.5(\mathrm{t} \times \mathrm{t})$ & Yes & 493.84 & 514.63 & 435.04 \\
\hline $\mathrm{T} 2-24$ & $\mathrm{C}$ & - & 20node & $t \times t$ & Yes & 511.47 & - & 435.04 \\
\hline $\mathrm{T} 2-25$ & $\mathrm{~F}$ & - & 20 node & $0.5(\mathrm{t} \times \mathrm{t})$ & Yes & 523.73 & - & 435.04 \\
\hline $\mathrm{T} 2-26$ & $\mathrm{C}$ & - & 20 node & $t \times t$ & Yes & - & 529.24 & 435.04 \\
\hline $\mathrm{T} 2-27$ & $\mathrm{~F}$ & - & 20node & $0.5(\mathrm{t} \times \mathrm{t})$ & Yes & - & 541.21 & 435.04 \\
\hline
\end{tabular}

Notes: $\mathrm{F}=$ fine mesh; $\mathrm{C}=$ coarse mesh

in order to assess them with respect to their fatigue strength. This paper has presented the details of hot spot stress evaluation based on the current methodologies for Hot Spot Approach of welded structures and then suggested an adequate evaluation method of using finite element analysis and experimental studies based on a round-robin study. 
Following insights have been derived based on the median results from the round-robin study:

- From the series of evaluation of the hot spot stress for tension loading: No significant differences were found between linear and quadratic extrapolations in evaluating the hot spot stress. There were negligible differences between the results achieved using small order and high order elements.

- From the evaluation of the hot spot stress for bending loading it was found that: The effect of high order elements and number of node may be sufficiently small to ensure convergence. In the evaluation of hot spot stress, the use of solid elements is recommended than the shell element when the dominant loading pattern is out-of-plane bending.

- From the evaluation of the hot spot stress for bending loading: it is recommended that the quadratic extrapolation method can give the most reasonable results as an extrapolation method.

- Additional scatter of the stress results is expected due to the usage of different element types offered by finite element programs and due to different techniques of modelling the weld, particularly if shell and solid elements are applied.

- In addition, the investigations of RR study have shown that also the meshing outside the stress evaluation area in the vicinity of the weld toe can further affect the results, so that mesh-insensitivity remains generally questionable.

- Also, the designer should be aware of the limitations set by the finite element model as well as by the evaluation method of the structural hot-spot stress.

The findings of this study should be included in the design codes as the current design codes do not give explicit methods for designers to distinguish the uncertainty of hot spot stress in reference stress used in fatigue strength determination.

Based on this result, it has been revealed that the hot spot stress approach depends on how hot spot stresses are defined and, in the case of numerical analysis, on the modeling of the structure and the weld geometry.

These investigations clarify the recommended application fields of the hot spot stress approach within the current guidelines. This study gives useful information on the possible variance on the evaluation of structural reference stress in the welded structures.

\section{ACKNOWLEDGEMENTS}

This work was supported by the Financial Supporting Project of Long-term Overseas Dispatch of PNU's Tenure-track Faculty.

Authors are thankful for the support of Advanced Ship Engineering Research Center (ASERC), Korea. The author is pleased to acknowledge the support of the LRET (Lloyd's
Register Educational Trust) via the LRET Research Center of Excellence at Pusan National University.

\section{REFERENCES}

ANSYS, 2006. User's Manual, Houston: Swanson Analysis Systems Inc.

American Bureau of Shipping (ABS), 1992. Guide for fatigue strength assessment of tankers, Part 3 Steel Vessel Rules. American Bureau of Shipping, New York.

Det Norske Veritas (DNV), 2008. Fatigue Design of Offshore Steel Structures. Recommended Practice DNV-RP-C203, Det Norske Veritas.

Doerk, O., Fricke, W. and Weissenborn, C., 2003. Comparison of different calculation methods for structural stresses at welded joints. International Journal of Fatigue, 25(5), pp. 359-369.

Dong, P., 2001. A structural stress definition and numerical implementation for fatigue analyses. International Journal of Fatigue, 23(10), pp. 865-76.

Dong, P. Hong, J.K. and Cao, Z., 2002. Structural stress based master $S-N$ curve for welded joints. IIW Doc. XIII-193002/XV-1119-02. International Institute of Welding.

Eurocode 9, 1998. Design of aluminum structures - Part 2: Structures susceptible to fatigue. EN 1999-2:1998 E, British Standard, London.

Fricke, W., 2002. Evaluation of Hot Spot Stresses in Complex Welded Structures. Proceedings of the IIW Fatigue Seminar, Tokyo Institute of Technology.

Fricke, W. and Kahl, A., 2005. Comparison of different structural stress approaches for fatigue assessment of welded ship structures. Marine Structures, 18, pp. 473-488.

Fricke, W. Petershagen, H. and Paetzold, H., 1998. Fatigue Strength of Ship Structures-Expample. GL-Technology, 1/1998, Germanischer Lloyd, Hamburg, Germany.

HKS, 2007. ABAQUS User's manual, Pawtucket, RI.

Hobbacher, A., 2009. The new IIW recommendations for fatigue assessment of welded joints and components - A comprehensive code recently updated. International Journal of Fatigue, 31(1), pp. 50-58.

Hobbacher A. (Ed), 2009. Recommendations for fatigue design of welded joints and components. IIW doc. XIII-1823-07. Welding Research Council Bulletin 520, New York.

I-DEAS, 1993. I-DEAS, FEM User's Guide, SDRC, Ohio.

Niemi, E., (Ed). 1995. Stress determination for fatigue analysis of welded components, IIW Doc XIII-1221-93. International Institute of Welding, Cambridge, Abington.

Petershagen, H. Fricke, W. and Massel, T., 1991. Application of the local approach to the fatigue strength assessment of welded structures in ship. IIW Doc. XIII-1409-91. International Institute of Welding.

Radaj, D., 1990. Design and analysis of fatigue-resistant welded structures. Abington Pub. Cambridge.

Xiao, Z.G. and Yamada, K., 2004. A method of determining geometric stress for fatigue strength evaluation of steel welded joints. International Journal of Fatigue, 26(12), pp. 1277-93. 